\title{
Human umbilical cord-derived mesenchymal stem cells ameliorate insulin resistance via PTEN- mediated crosstalk between the PI3K/Akt and Erk/MAPKs signaling pathways in the skeletal muscles of $\mathrm{db} / \mathrm{db}$ mice
}

\section{Guang Chen}

Taizhou University

Xiao-yan Fan

Taizhou University

Xiao-peng Zheng

Taizhou hospital, Taizhou University

Yue-lei Jin

Taizhou University

Ying Liu

Jilin Tuohua Bioengineering Company Limited

Shuang-chun Liu ( $\nabla$ dachun3065@163.com )

Municipal Hospital Affiliated Medical School of Taizhou University

\section{Research}

Keywords: HU-MSCs, insulin resistant, PTEN, crosstalk, PI3K/Akt, Erk/MAPK, db/db mice

Posted Date: February 24th, 2020

DOl: https://doi.org/10.21203/rs.2.24329/v1

License: (c) (i) This work is licensed under a Creative Commons Attribution 4.0 International License.

Read Full License

Version of Record: A version of this preprint was published on September 16th, 2020. See the published version at https://doi.org/10.1186/s13287-020-01865-7. 


\section{Abstract}

Background: Globally, 1 in 11 adults have diabetes mellitus and 90\% of the cases are type 2 diabetes mellitus (T2DM). Asia is the epicenter of this global T2DM epidemic. T2DM and its complications have contributed significantly to the burden of mortality and disability worldwide. Insulin resistance (IR) is a central defect in T2DM, and although multiple drugs have been developed to ameliorate IR, the limitations and accompanying side effects cannot be ignored. Thus more effective methods are required to improve IR.

Methods: In the current study, $\mathrm{db} / \mathrm{m}$ and $\mathrm{db} / \mathrm{db}$ mice were injected with human umbilical cord-derived mesenchymal stem cells (HUC-MSCs) via tail vein injection (IV), intraperitoneal injection (IP) and skeletal muscle injection (IM). Body weight, fasting blood glucose and the survival rates were monitored. Furthermore, the anti-IR effects and potential mechanisms of transplanted HUC-MSCs were investigated in $\mathrm{db} / \mathrm{db}$ mice in vivo.

Results: The results showed that HUC-MSC transplantation by IM was safer compared with IV and IP, and the survival rate reached $100 \%$ in the IM transplanted mice. HUC-MSCs can stabilize localization and differentiation in skeletal muscle tissue and significantly ameliorate IR. Potential regulatory mechanisms are associated with downregulation of inflammation; regulating the balance between PI3K/Akt and ERK/MAPK signaling pathway via PTEN, but was not associated with the IGF-1/IGF-1R signaling pathway.

Conclusions: These results suggest HUC-MSC transplantation by IM may be a novel therapeutic direction to prevent IR and increase insulin sensitivity.

\section{Introduction}

Diabetes mellitus is a life-long metabolic disease with high morbidity and mortality rates, and DM reduces the patients' quality of life due to acute and chronic complications [1,2]. Type 2 diabetes mellitus (T2DM) accounts for $90-95 \%$ of diabetes mellitus cases, affecting 380 million individuals worldwide [3] .

T2DM is the pathological consequence of two concurrent and interacting conditions, insulin resistance (IR) and relative insulin deficiency. On the one hand, insulin's ability to suppress hepatic glucose output and stimulate glucose uptake and utilization is impaired resulting in chronically raised insulin levels, and on the other hand, the capacity of the pancreatic $\beta$-cells to maintain a hyperinsulinemic state also begins to fail $[4,5]$. T2DM patients are rarely hypoinsulinemic when compared to nondiabetic individuals [4]. Additionally, there is also a degenerative process that affects the normal healthy pancreatic $\beta$-cells. In a landmark study, it was shown that after a certain point, a relatively small decrease in $\beta$-cell mass is all that is required to have profound effects on fasting blood glucose levels [6]. 
Dysregulation of the insulin signaling cascade results in insulin resistance, which has important consequences on the regulation of glucose and lipid metabolism. The two major pathways of insulin receptor signal transduction are the insulin receptor substrate (IRS)-PI3K-Akt (also known as PKB) pathway and the growth factor receptor-bound protein 2 (Grb2)-son of sevenless homologue 1 (SOS)-RasMAPK pathway (also known as the ERK pathway) [7]. Akt serves as a central node in the regulation of the biological effects of insulin. The insulin-induced Grb2-SOS-Ras pathway results in activation of the MAPK pathway and is a major regulator of cell proliferation and differentiation. Insulin signal transduction must be tightly controlled to avoid severe metabolic and proliferative perturbations. Negative regulators of this signal transduction are often activated by insulin; this feedback mechanism inhibits the signaling pathways at the critical nodes, either insulin receptor-IRS or Akt. Dysregulation of negative regulators of insulin signal transduction via chronic hyperactivation contributes to the development of insulin resistance. These negative regulators include PTEN. PTEN reduces insulin sensitivity by inhibiting the $\mathrm{PI3K} / \mathrm{v}$-Akt murine thymoma viral oncogene homologue (Akt) pathway [8]. Increased levels of PTEN were reported in the aortas of streptozotocin-induced type 1 diabetic mice [9] and skeletal muscles of mice with T2DM $[10,11]$.

With the development of research technologies, epigenetics studies showed that stem cells are pluripotent and this achieved via cellular reprogramming techniques. Thus, alternative therapeutic approaches allowed for new advances and improved understanding of stem cell therapy [12]. At present, human umbilical cord-derived mesenchymal stem cells (HUC-MSCs) are widely used in clinical treatments as they are a rich source of self-replicating cells with a high degree of differentiation potential, and extremely low immunogenicity and immunoreactivity [13]. Several studies have shown that treatment with HUC-MSCs showed impressive therapeutic effects in diabetes [14, 15]. HUC-MSCs can control blood sugar levels effectively via restoring islet function and ameliorating IR.

In the present study, the treatment and anti-IR effects of HUC-MSCs were further investigated in $\mathrm{db} / \mathrm{db}$ mice. The multiple targeted mechanisms of HUC-MSCs in vivo were also investigated, and may serve as potential treatments for IR in T2DM.

\section{Materials And Methods}

\section{Reagents}

Mouse insulin (EMD Millipore), TNF-a and IL-6 (Abcam) ELISA kits, anti-DNA (cat. no. AC 30-10) monoclonal antibody (Novus Biologicals, Ltd.), D-Luciferin, sodium salt D-Fluorescein sodium salt (cat. no. 40901ES01; Shanghai Yeasen), LUC-labeled lentiviral particles packaged HUC-MSCs (Shanghai; Yeasen), RIPA lysis buffer, nitrocellulose membranes and an SABC (rabbit lgG)-POD kit were obtained from Beijing Solarbio Science \& Technology Co., Ltd. A blood glucose meter and test strips were acquired from ACCU-CHEK (Accu-Chek Softclix;). TRIzol ${ }^{\circledR}$ was purchased from Invitrogen (Thermo Fisher Scientific, Inc.). Antibodies against PI3K, P85, phospho-PI3K P85 (cat. no. Y607), insulin receptor $\beta$ (IR), p-IR (cat. no. Y1185); PTEN, p-PTEN (cat. no. S380+T382+T383), glucose transporter 4 (cat. no. GLUT4) and IGF-1R 
were obtained from Abcam. Antibodies against Akt, p-Akt (ser 473), ERK and p-ERK (1/2) (Thr202/Tyr204) were obtained from Cell Signaling Technology, Inc. Anti-GAPDH, anti-mouse IgG, and anti-rabbit IgG were obtained from Cell Signaling Technology, Inc. Other reagents used were of analytical grade.

\section{Animals and experimental design}

Six-week old female db/db mice (18-20 g) were purchased from Model Animal Research Center of Nanjing University. All mice were housed individually with a $12 \mathrm{~h} \mathrm{light/dark}$ cycle at $23 \pm 2^{\circ} \mathrm{C}$ and a humidity of $55 \pm 10 \%$, with free access to water and food. The mice were allowed to adapt to these conditions for one week prior to beginning the experimental procedures. The animal procedures were approved by the Animal Care and Use Committee on the Ethics of Animal Experiments of Taizhou University of Science and Technology. All related facilities and experimental procedures were performed according to the guidelines described by the Technical Standards for the Testing \& Assessment of Health Food (2003).

\section{Cell culture}

HUC-MSCs were provided by Jilin Tuohua Bioengineering Co. Ltd. (Siping). HUC-MSCs were immediately obtained from healthy mothers during routine term elective caesarean section births. Fully informed consent was obtained several weeks prior to delivery. Ethics approval was obtained from the Ethics Committee of the Siping Center Hospital (approval no. SC-2017-010). HUC-MSCs were isolated and propagated, as previously described [16].

\section{HUC-MSCs treatment study}

The $\mathrm{db} / \mathrm{db}$ mice were divided into four groups: $\mathrm{db} / \mathrm{m}(\mathrm{n}=10), \mathrm{db} / \mathrm{m}+\mathrm{HUC}-\mathrm{MSC}$ (intraperitoneal injection, IP; $n=10$ ), db/m+HUC-MSCs (tail vain injection, IV; $n=10$ ), db/m+HUC-MSCs (skeletal muscle injection, IM; $n=10), d b / d b(n=15), d b / d b+H U C-M S C s$ (intraperitoneal injection, IP; $n=15), d b / d b+H U C-M S C s$ (tail vain injection) and db/db+HUC-MSCs (skeletal muscle injection). A total of $1 \times 10^{7}$ HUC-MSCs (passage 4) were resuspended in $0.7 \mathrm{ml}$ saline and administered by IP/IV; or $1 \times 10^{8}$ (passage 4) in $2 \mathrm{ml}$ saline were administered by local injection IM for the $\mathrm{db} / \mathrm{m}+\mathrm{HUC}-\mathrm{MSC}$ and $\mathrm{db} / \mathrm{db}+\mathrm{HUC}-\mathrm{MSC}$ groups. The other groups were given an equivalent volume of saline as the $\mathrm{db} / \mathrm{m}$ and $\mathrm{db} / \mathrm{db}$ groups, and both groups were fed a normal chow diet. To determine the effect of HUC-MSCs, survival rate, weight, blood glucose, ALT, AST, Cre, BUN, $y-G T$ and the levels of serum insulin, were measured at the mentioned times.

\section{Bioluminescence imaging}

The HUC-MSCs-luc skeletal muscle transplantation $\mathrm{db} / \mathrm{db}$ mice were anesthetized using isoflurane, and injected intraperitoneally with $100 \mu \mathrm{l}$ of $15 \mathrm{mg} / \mathrm{ml}$ D-luciferin in Sodium salt D solution (Yeasen). Subsequently, the mice were imaged using an in vivo imaging system (FOBI; Berthold Technologies). In vivo imaging was performed prior to sacrifice. 


\section{Histological examination of the skeletal muscle}

A portion of the extracted skeletal muscle was immediately fixed in PBS mixed with $4 \%$ paraformaldehyde and embedded in paraffin. The sections ( $4 \mu \mathrm{m}$ in thickness) were stained with hematoxylin and eosin (H区E). Histological analysis was performed using a light microscope (DM4000B photomicroscope; Leica Microsystems, Inc.).

\section{Immunofluorescence (IF) studies}

Skeletal muscle sections were subjected to signal-direct IF staining of human DNA (1:10; ANA), followed by incubation with Alexa Flour 488-conjugated secondary antibodies (OriGene Technologies, Inc.). Nuclei were counterstained with Hoechst (Invitrogen; Thermo Fisher Scientific, Inc.). All sections were scanned, and images were acquired using a laser scanning confocal microscope (FV1000; Olympus Corporation).

\section{Immunohistochemical (IHC) staining}

After de-paraffinization, the sections were incubated with a $3 \% \mathrm{H}_{2} \mathrm{O}_{2}$ solution to block endogenous peroxidases. Antigen retrieval was performed using $0.1 \mathrm{M}$ sodium citrate $(\mathrm{pH} 6.0)$ for $60 \mathrm{~min}$. Sections were incubated with anti-PI3K, anti-GLUT4, anti-p-IR, anti-p-PTEN (1:100; Abcam), or anti-p-ERK (1:100; CST) antibodies overnight at $4^{\circ} \mathrm{C}$, and a horseradish peroxidase-conjugated secondary antibody and diaminobenzidine substrate were added sequentially. Following hematoxylin counterstaining and dehydration, the sections were mounted and observed using a Leica M4000B photomicroscope (Leica Microsystems, Inc.).

\section{ELISA}

The concentrations of TNF-a, IL-6 (all from Abcam) and serum insulin (EMD Millipore) were determined using specific ELISA kits.

\section{Reverse transcription-quantitative (RT-q)PCR}

Gene expression of c-fos, c-myc, JNK, GSK-3ß, FOX01, GLUT4, PTEN and IRS-1 was analyzed using RTqPCR. TRIzol ${ }^{\circledR}$ reagent was used to extract RNA, and CDNA was synthesized using a reverse transcription kit (Takara Bio, Inc.). qPCR containing was performed using a SYBR Premix EX Taq ${ }^{T M}$ CDNA with specific gene primers, and genes were amplified using a 7300 PULAS system (Applied Biosystems; Thermo Fisher Scientific, Inc.). The relative expression of each gene was determined and normalized to the expression of $18 \mathrm{~S}$ and calculated using the $2^{-\Delta \Delta C} \mathrm{q}$ method. The sequences of the primers used are: 18S-forward $5^{\prime}-$ ACTCAACACGGGAAACCTCAC-3' and reverse, 5'-TCGCTCCACCAACTAAGAACG-3'; c-fos-forward, 5'GGAATTAACCTGGTGCTGGATTG-3' and reverse, 5'-GAACATTGACGCTGAAGGACTAC-3'; c-myc-forward, 5'CTATCACCAGCAACAGCAGAG-3' and reverse, 5'-ACATAGGATGGAGAGCAGAGC-3'; JNK-forward, 5'ACATAGGATGGAGAGCAGAGC-3' and reverse, 5'-CATTGACAGACGGCGAAGAC-3'; GSK-3ß-forward, 5'CACCGCTCCTTCCTTCCTTC-3' and reverse, 5'-GACTCCTCTTCCTAACCACCTG-3'; Fox01-forward, 5'CAGCCTTGAGCAGCCTAATG-3' and reverse, 5'-AGACTGGGAAACACCGATGG-3'; GLUT4-forward, 5'- 
ACGGATAGGGAGCAGAAACC-3' and reverse, 5'-CAGCACAGGACACTCATCTTC-3'; PTEN-forward, 5'AGAGATTGGCTGCTGTCCTG-3' and reverse, 5'-TGGTTAAGTCATTGCTGCTGTG-3'; IRS-1-forward, 5'AGCAGCAGTAGCAGCATCAG-3' and reverse, 5'-TTACCGCCACCACTCTCAAC-3'; IGF-1-forward, 5'TATGGAGATGGGAGGGTTTCAG-3' and reverse, 5'-GTAGGCACAGCATTCGTTAGG-3'; mTOR-forward, 5'GCAGCAACAGTGAGAGTGAAG-3' and reverse, 5'-CAAGGAGATAGAACGGAAGAAGC-3'.

\section{Western blot analysis}

Protein samples were resolved using 8 or 10\% SDS-PAGE and transferred to PVDF membranes (EMD Millipore). Membranes were blocked in $5 \%$ nonfat dry milk, and subsequently incubated with primary antibodies against p-PI3K/PI3K, p-AKT/Akt, p-IR/IR, p-PTEN/PTEN and IGF-1R (1:500; Abcam), pERK/ERK1/2 and GAPDH (1:500; CST Biological Reagents Co., Ltd.) overnight. Horseradish peroxidaseconjugated anti-rabbit IgG or anti-mouse IgG (1:7,000; CST Biological Reagents Co., Ltd.) were used as the secondary antibodies. PVDF membranes were developed using an Image-Pro Plus system.

\section{Statistical analysis}

Data are represented as the mean \pm standard deviation and analyzed using a one-way ANOVA or a twotailed unpaired Student's t-test. P-values were adjusted for multiple comparisons using Bonferroni correction. Analyses were performed using GraphPad Prism version 7 (GraphPad Software, Inc.). P<0.05 was considered to indicate a statistically significant difference.

\section{Results}

\section{Therapeutic effects of transplanted HUC-MSCs in $\mathrm{db} / \mathrm{db}$ mice}

To evaluate the potential capacity of HUC-MSCs and the effect of administration route, FBG, weight and survival rates were assessed. The HUC-MSCs were administered by three clinically relevant routes; IV, IP and IM. These different transplantation routes resulted in different FBG levels, but did not have any effect on weight in the $\mathrm{db} / \mathrm{db}$ mice. Although administration of cells using IV was the best method for controlling FBG, IV administration resulted in the lower survival rate of $71.9 \%$. HUC-MSC transplantation by IM also reduced the FBG and the survival rate was $100 \%$. Thus IM transplantation was deemed to be the safest and most effective method of clinical application of HUC-MSCs.

In addition, HUC-MSC transplantation did not result in injury to the liver and kidneys in mice. The levels of ALT, AST, $Y-G T$, Cre and BUN in serum were measured $72 \mathrm{~h}$ after HUC-MSC transplantation. The results found that HUC-MSC transplantation did not have any adverse effects on liver and kidney toxicity regardless of the administration routes.

\section{HUC-MSC treatment ameliorates IR in the skeletal muscle of $\mathrm{db} / \mathrm{db}$ mice}

To facilitate longitudinal cell tracking in vivo imaging, HUC-MSCs were transiently engineered with the firefly luciferase gene using recombinant adenovirus transduction. The results showed that HUC-MSCs 
stably colonized in the skeletal muscle following IM transplantation. Although fluorescent signals were detected in the bladder region $1.5 \mathrm{~h}$ after transplantation, these signals were absent after $2 \mathrm{~h}$ (Fig. 2A). Subsequently, the proliferation and differentiation of HUC-MSCs in skeletal muscle were assessed. The HUC-MSCs were labeled using an anti-nuclear antibody (ANA) and the expression of ANA was determined using IF. Consistent with Braid et al [17], ANA expression in skeletal muscles were significantly increased following IM implantation in the $\mathrm{db} / \mathrm{db}+\mathrm{HUC}-M S C$ s mice compared with the $\mathrm{db} / \mathrm{db}$ mice (Fig. 2B). Thus, IM implantation highlights the potential clinical benefits of the prolonged presence of MSCs at a homeostatic implant site using a minimally invasive delivery route suitable for numerous applications.

Subsequently, IR was calculated as follows: HOMA IR = serum insulin mmol/l $\mathrm{x}$ blood glucose mmol/l/22.5 [18]. The mean HOMA IR was significantly decreased in $\mathrm{db} / \mathrm{db}+\mathrm{HUC}$-MSCs mice compared with $\mathrm{db} / \mathrm{db}$ mice $(\mathrm{P}<0.01)$. However, HUC-MSC implantation did not significantly alter the HOMA IR in the $\mathrm{db} / \mathrm{m}$ mice (Fig. 2C).

\section{HUC-MSCs treatment alleviates inflammation of the skeletal muscle in $\mathrm{db} / \mathrm{db}$ mice}

Nutrient overload induces low-grade chronic inflammation of adipose tissue, skeletal muscle, liver, pancreas and the hypothalamus [19]. In the present study, inflammatory cell infiltration was significantly higher in the $\mathrm{db} / \mathrm{db}$ compared with the $\mathrm{db} / \mathrm{db}+$ HUC-MSCs mice (Fig. 3A).

The secretion of IL-6, TNF- $a$ and Resistin are shown in Fig. 3B. There were no significant differences in the secretion of any of the factors between $\mathrm{db} / \mathrm{m}$ and $\mathrm{db} / \mathrm{m}+\mathrm{HUC}-M S C$ s mice. However, the expression levels of IL-6 and TNF-a were significantly lower in $\mathrm{db} / \mathrm{db}$ mice with HUC-MSC transplantation compared with the untransplanted mice $(\mathrm{P}<0.01$; Fig. $3 \mathrm{~B})$.

\section{HUC-MSCs treatment ameliorates IR through regulating the activation of PI3K/Akt signaling in the skeletal muscle of $\mathrm{db} / \mathrm{db}$ mice}

Disruption of the insulin signaling pathway is one of the primary causes of IR [20], including the IRS1/PI3K/Akt signaling pathway [21]. To further investigate the effect of HUC-MSC implantation on the $\mathrm{PI3K} /$ Akt signaling pathway, the expression levels of members of the PI3K/Akt signaling pathway in skeletal muscle tissue were assessed using IHC, western blotting and RT-qPCR. The IHC results showed that the expression of PI3K, p-Akt and GLUT4 were increased in the $\mathrm{db} / \mathrm{db}+\mathrm{HUC}-\mathrm{MSC}$ mice compared with the $\mathrm{db} / \mathrm{db}$ mice (Fig. 4A). The expression of p-PI3K/PI3K, pAkt/Akt and p-IR/IR in skeletal muscle tissue were assessed using western blotting, and the ratio of p-PI3K/PI3K, pAkt/Akt and p-IR/IR expression were increased in the $\mathrm{db} / \mathrm{db}+\mathrm{HUC}$-MSCs mice compared with the $\mathrm{db} / \mathrm{db}$ mice $(P<0.05$ and $\mathrm{P}<0.01$; Fig. 4B). The mRNA expression levels of IRS-1, GLUT4 and Foxo1 were noticeably increased in the $\mathrm{db} / \mathrm{db}$ mice transplanted with HUC-MSCs, and the mRNA expression levels of mTOR and GSK-3 $\beta$ were significantly decreased in the $\mathrm{db} / \mathrm{db}$ mice transplanted with HUC-MSCs compared with $\mathrm{db} / \mathrm{db}$ mice $(\mathrm{P}<0.05$ and $\mathrm{P}<0.01$; Fig. $4 \mathrm{C})$. 


\section{HUC-MSC treatment ameliorates IR through regulating the activation of ERK/MAPK signaling in the skeletal muscle of $\mathrm{db} / \mathrm{db}$ mice}

MAPK-dependent signal transduction is crucial for an array of metabolic events and aberrant MAPK signaling is associated with the development of type 2 diabetes and metabolic syndrome [22]. To investigate the effects of HUC-MSC implantation on the ERK/MAPK signaling pathway, the expression levels of members of the ERK/MAPK signaling pathway were determined in skeletal muscle tissues using $\mathrm{IHC}$, western blotting and RT-qPCR. IHC results showed that the expression of ERK was decreased in $\mathrm{db} / \mathrm{db}+$ HUC-MSCs mice compared with $\mathrm{db} / \mathrm{db}$ mice (Fig. 5A). The expression of $\mathrm{p}$-ERK/ERK in skeletal muscle tissues was measured using western blotting, and the ratio of $\mathrm{p}$-ERK/ERK expression was also decreased in the $d b / d b+H U C-M S C s$ mice compared with $d b / d b$ mice $(P<0.01 ;$ Fig. $5 B)$, whereas the mRNA expression levels of $\mathrm{JNK}$, c-fos and c-myc were significantly decreased in the $\mathrm{db} / \mathrm{db}$ mice transplanted with HUC-MSCs compared with the $\mathrm{db} / \mathrm{db}$ mice $(P<0.05, P<0.01$; Fig. $5 C)$.

\section{HUC-MSC treatment regulates the balance between PI3K/Akt and Erk/MAPK signaling by increasing PTEN transcription and expression in the skeletal muscle of $\mathrm{db} / \mathrm{db}$ mice}

Studies have reported that PTEN may coordinate the effects of insulin on both the PI3K and the MAPK pathway [23]. To further investigate the effect of PTEN on PI3K/Akt and Erk/MAPK signaling in $\mathrm{db} / \mathrm{db}$ mice with HUC-MSC transplantation, the effect of PTEN in skeletal muscle tissues was determined. The results showed that the protein expression levels of PTEN and p-PTEN were decreased in $\mathrm{db} / \mathrm{db}+\mathrm{HUC}$ MSCs mice compared with $\mathrm{db} / \mathrm{db}$ mice (Fig. $6 \mathrm{~A}$ and $\mathrm{B} ; \mathrm{P}<0.01$ ). In addition, the mRNA expression levels of PTEN exhibited similar changes as the changes in the protein expression levels (Fig. 6C).

\section{HUC-MSCs treatment ameliorates IR but this is not associated with the IGF-1/IGF-1R pathway}

IGF-1R serves a significant role in insulin signaling. IGF-1 and IGF-1R are known to maintain insulin sensitivity in different tissues [22]. To determine whether HUC-MSC transplantation improved insulin sensitivity was associated with the IGF-1/IGF-1R pathway, the expression of IGF-1 and IGF-1R in skeletal muscle tissue of $\mathrm{db} / \mathrm{db}+\mathrm{HUC}-\mathrm{MSC}$ mice was assessed. Only the expression of IGF-1 mRNA was reduced by HUC-MSC implantation compared with $\mathrm{db} / \mathrm{db}$ mice ( $\mathrm{P}<0.01$; Fig. 7B). However, HUC-MSC transplantation did not result in changes to the protein expression levels of IGF-1R in $\mathrm{db} / \mathrm{db}+\mathrm{HUC}-\mathrm{MSC}$ mice (Fig. 7A).

\section{Discussion}

IR is a central defect in metabolic syndromes such as T2DM, and serves a critical role in the progression from pre-T2DM to T2DM. Despite the development of multiple drugs to ameliorate IR, the limitations of the accompanying side effects are still notable and should not be ignored. Therefore, development of a more effective method to improve IR is required. Recently, there has been a focus on the link between HUC-MSC transplantation and IR [13]. The present study investigated the anti-IR effects and potential mechanisms of HUC-MSC transplantation in $\mathrm{db} / \mathrm{db}$ mice in vivo. The results showed that IM HUC-MSC 
transplantation was safer compared with IV and IP administration, and the survival rate of IM transplantation reached $100 \%$. HUC-MSCs stabilized localization and differentiation in the skeletal muscle, and significantly ameliorated IR. Potential regulatory mechanisms underlying the effects of HUCMSCs were associated with downregulation of inflammation, and PTEN-mediated regulation of the balance between PI3K/Akt and ERK/MAPK signaling pathways, and were not associated with the IGF1/IGF-1R pathway. This suggests that HUC-MSCs may be a potential novel therapeutic agent for the clinical prevention of IR and associated diseases.

MSCs, as a source of seed cells, have garnered increasing attention in the field of stem cell therapy. The human umbilical cord is a safe and rich source of stem cells and a reliable source of MSCs, in addition to bone marrow MSCs [24-26]. At present, a large number of studies have discussed the clinical efficacy of stem cell therapy [27-29]; however, the safety and effectiveness of the optimal route for HUC-MSC transplantation have not been extensively considered. The safety of MSC administration has been reported in numerous clinical trials [30-36]. At present, IV infusion is the standard practice for delivering cell therapies. However, numerous studies have consistently demonstrated that IV-infused cells largely become trapped in the capillaries of the lungs, where they fail to survive longer than a few days $[13,35$, 37-41]. This phenomenon reduces the potential therapeutic benefit of the administered MSCs, a limitation cited in both clinical trials and animal studies $[33,42,43]$. In contrast, studies recently reported that engineered MSCs administered by IM were still detectable at the implant site > 100 days after transplantation, and they continued to secrete a functional antibody into circulation [44]. Thus, in the present study, three routes of HUC-MSC transplantation in $\mathrm{db} / \mathrm{db}$ mice were compared. The survival rate of $\mathrm{db} / \mathrm{db}$ mice was $100 \%$ with IM transplantation compared with $71.4 \%$ for IV and $85.7 \%$ for IP. Additionally, HUC-MSCs stabilized localization, proliferation and differentiation in the skeletal muscle. IM implantation presents a useful alternative to achieve clinical benefits from prolonged MSC presence at a homeostatic implant site, and is a minimally invasive delivery route suitable for several applications [16]. HUC-MSCs significantly ameliorated IR via IM injection in $\mathrm{db} / \mathrm{db}$ mice. Thus, IM administration was shown to be more preferable than IV or IP infusion for treatment of IR and other related diseases. However, optimized thawing protocols that restore the full biological potential of cryo-preserved MSC therapies prior to implantation must be developed.

IR is increasingly considered to be associated with low-grade systemic chronic inflammation, which has a central role in the pathogenesis of T2DM $[45,46]$. Inflammatory pathways have been suggested as the underlying unifying pathogenic mediators for excess weight, diabetes mellitus and cardiovascular diseases [47]. Since Hotamisligil et al [48] initially demonstrated that TNF-a can be induced in a T2DM rodent model, increasing attention has been placed on the connection between inflammation and IR. Another study in individuals revealed that, during obesity, elevated levels of $C$ reactive protein and IL- $1 \beta$ in the blood were predictive indicators of the development of T2DM [49]. Therefore, chronic inflammation has been recognized as a critical inducer in the development of IR and T2DM. Consistently, in the animal experiments of the present study, HUC-MSC transplantation significantly decreased the inflammatory response in skeletal muscle tissue of $\mathrm{db} / \mathrm{db}$ mice, and decreased the levels of TNF- $\mathrm{a}$ and IL-6 production in the peripheral blood compared with those in the model group. Thus, these findings suggest that HUC- 
MSC transplantation can decrease a low-degrade inflammatory response, and this may underlie the amelioration of insulin resistance.

Upon insulin stimulation, two signaling pathways are activated. The insulin receptor is able to recruit and phosphorylate IRS proteins following ligand binding, leading to the activation of the PI3K/Akt pathway, which is responsible for glucose metabolism, including glucose uptake and glycogenesis [50-53]. Additionally, insulin stimulation activates the MAP kinases (Erk 1 and 2) and SAP kinases (JNK and p38MAPK), which results in decreased insulin signaling and is crucial for insulin resistance [54-56]. In the present study, HUC-MSC transplantation significantly induced activation of PI3K/Akt signaling, thus increasing the expression of p-PI3K, p-Akt, GLUT4 and p-IR protein compared with $\mathrm{db} / \mathrm{db}$ mice. Additionally, the expression of IRS, GLUT4 and FoxO1 mRNA were increased in $\mathrm{db} / \mathrm{db}$ mice transplanted with HUC-MSCs. However, the expression levels of GSK3 $\beta$ and mTOR were decreased in $\mathrm{db} / \mathrm{db}$ mice transplanted with HUC-MSCs compared with the db/db mice (Fig. 4C). IRS proteins, which are crucial regulators of the insulin and IGF signaling pathways, are important in the linkage of membrane receptors to intracellular substrates, and can activate different intracellular signaling pathways, including PI3K [22, 57]. Studies have shown that disruption of GLUT4 expression in adipose tissues or muscles results in global IR [58]. Importantly, in skeletal muscle cells, the quantity of GLUT4 is largely controlled at the level of transcription [59]. Furthermore, accumulating evidence suggests that FoxO1 is a key transcription factor responsible for regulation of insulin signaling, and knockdown of FoxO1 improved insulin sensitivity [60]. In the present study, HUC-MSC transplantation increased the expression of Fox01 mRNA compared with $\mathrm{db} / \mathrm{db}$ mice, although the expression levels were lower compared with the $\mathrm{db} / \mathrm{m}$ mice. However, studies have reported that mTORC2 phosphorylates and activates Akt, and mTORC1 levels are decreased by suppression of tuberous sclerosis protein 2 following the activation of Akt. mTORC2 suppress Foxo1 forkhead transcription factor promotes gluconeogenesis, mediating the effects of insulin on the suppression of hepatic glucose production [61]. In contrast to these previous studies, the mRNA expression levels of total mTOR and GSK3 $\beta$ mRNA were decreased in the $\mathrm{db} / \mathrm{db}+$ HUC-MSCs mice; the primary reason for this inconsistency may be that total mTOR mRNA levels were detected, not mTORC1 or mTORC2 mRNA individually. In addition, activation of Akt serves an important role in fundamental cellular functions, such as cell proliferation and survival by phosphorylating its downstream substrates, including GSK3 $\beta$, and thereby inactivating them [62]. Thus, the results of the present study showed that HUC-MSC transplantation improved IR, and this was associated with a decrease in the activity of the $\mathrm{PI} 3 \mathrm{~K} /$ Akt signaling pathway.

HUC-MSC transplantation significantly decreased activation of the ERK/MAPK signaling Pathway, thus decreasing the expression of $\mathrm{p}$-ERK compared with $\mathrm{db} / \mathrm{db}$ mice. Additionally, the mRNA expression levels of JNK, c-fos and c-myc mRNA were decreased in the $\mathrm{db} / \mathrm{db}$ mice transplanted with HUC-MSCs. Numerous studies found that MAPK-dependent signal transduction is crucial for an array of metabolic events and inappropriate MAPK signaling is associated with the development of type 2 diabetes and metabolic syndrome [22]. ERK activity is induced in human adipose tissues during a diabetic state. Furthermore, diabetogenic factors may influence insulin signaling through activation of ERK; hence inhibition of the ERK pathway has been considered as a therapeutic approach to treat IR [63]. Recent 
studies have described JNK as a new paradigm at the crossroads of adiposity, metabolic inflammation and IR [22]. Mechanistically, JNK can interfere with insulin signaling through direct phosphorylation of IRS, promoting metabolic inflammation, suppressing the pituitary thyroid axis and negatively regulating PPARa activity and fibroblast growth factor 21 expression. Furthermore, deletion of JNK has been demonstrated to improve insulin signaling and glucose tolerance [64]. In the present study, it was shown that HUC-MSC transplantation decreased the activation of ERK and JNK expression. Therefore, HUC-MSC transplantation may be used as a therapeutic approach to improve IR.

Accumulating evidence has suggested that the PI3K/Akt and ERK/MAPK pathways are activated due to a loss of phosphatase and PTEN function [65], and PTEN is a negative regulator of the PI3K signaling pathway $[66,67]$. To evaluate the potential capacity of PTEN in regulating the balance between PI3K/Akt and ERK/MAPK pathway in HUC-MSCs treated $\mathrm{db} / \mathrm{db}$ mice, the expression of PTEN was assessed using IHC, western blotting and RT-qPCR. The expression levels of PTEN and p-PTEN protein were decreased in the $\mathrm{db} / \mathrm{db}+$ HUC-MSCs mice compared with $\mathrm{db} / \mathrm{db}$ mice. In addition, the mRNA expression levels of PTEN were also decreased Consistently, upregulation of PTEN expression inhibited the activation of the $\mathrm{PI3K} /$ Akt signaling pathway, increased the activation of the ERK/MAPK signaling pathway, and thus increased the incidence of IR. The balance between these two signaling pathways, is considered a key regulator of insulin sensitivity $[68,69]$. Therefore, identifying the key regulator for the coordination between these two signaling pathways may not only shed light on the mechanisms underlying insulin resistance, but also provide novel strategies for treatment of diabetes. PTEN is a potential regulator of the coordination between PI3K/Akt and MAPK signaling pathways, providing novel insights into the development of potential therapeutics for IR in diabetic patients in the future.

IGF-1 is a homologue molecule that acts predominantly as an anabolic hormone involved in cell growth, differentiation and migration [70]. IGF-1 exerts its biological functions through activation of IGF-1Rmediated downstream signaling pathways. IGF-1 exhibits 50\% amino acid sequence homology with insulin and elicits a similar hypoglycemic response [71]. In the present study, the expression of IGF-1 mRNA was decreased by HUC-MSC implantation compared with the $\mathrm{db} / \mathrm{db}$ mice. However, HUC-MSC transplantation did not alter the expression of IGF-1R protein in the $\mathrm{db} / \mathrm{db}+\mathrm{HUC}-\mathrm{MSC}$ mice. These results suggest that HUC-MSC transplantation-mediated improvement of IR in the skeletal muscle tissues of $\mathrm{db} / \mathrm{db}$ mice was not associated with regulation of the IGF-1/IGF-1R signaling pathway.

\section{Conclusions}

Together, these results demonstrate that IM HUC-MSC transplantation is the safer than IV or IP administration, and IM administration resulted in $100 \%$ survival rate of mice. HUC-MSCs can stabilize localization and differentiation in skeletal muscle tissue, and significantly ameliorate IR, and this was mediated by PTEN-mediated regulation of the balance between PI3K-Akt and Erk/MAPK signaling pathways. Furthermore, HUC-MSC implantation also downregulated expression of inflammatory markers in the skeletal muscle tissue. Thus, HUC-MSC transplantation may be a potential therapeutic direction for prevention of IR and increasing insulin sensitivity. 


\section{Abbreviations}

HUC-MSCs: human umbilical cord-derived mesenchymal stem cells; T2DM: type 2 diabetes mellitus; IR: insulin resistance; IV: tail vein injection; IP: intraperitoneal injection; IM: skeletal muscle injection; GLUT4: glucose transporter 4; IR: insulin receptor; H\&E: Hematoxylin and eosin; IF: immunofluorescence; IHC:Immunohistochemical; RT-qPCR: reverse transcription- quantitative PCR; ANA: anti-nuclear antibody; IL-6: interleukin-6; TNF-a: tumor necrosis factor-a; IRS-1: insulin receptor substrate-1; IGF-1: insulin-like growth factor-1.

\section{Declarations}

\section{Acknowledgments.}

No applicable.

\section{Authors' contributions}

The contribution of each author is as follows: GC and SCL conceived and designed the experiments. XYF, $\mathrm{XPZ}$ contributed to the model establishment, treatment and monitoring of mice, as well as data and sample collection throughout the experiments. YL performed culture and identification of HUC-MSC. XYF, YLJ and XPZ performed H区E, IHC, IF, Biochemical index quantification. GG and XYF performed WB and descriptive statistical analyses. GC and SCL wrote the manuscript.

\section{Funding}

This work has been supported by grants from Key project of the natural science foundation in Heilongjiang Province (ZD2017020); PhD star-up fund of Liaoning Province (20180540019).

\section{Availability of data and materials}

The datasets supporting the conclusions of this article are included within the article.

\section{Ethics approval and consent to participate}

Studies involving human tissue specimens were collected following the principles of the Declaration of Helsinki. Ethics approval was obtained from the Ethics Committee of the Siping Center Hospital (approval no. SC-2017-010). All animal experiments performed were in accordance with the institutional guidelines for animal research and approved by the Animal Care and Use Committee of Taizhou University.

\section{Consent for publication}

Not applicable.

\section{Competing interests}


The authors declare that they have no competing interests.

\section{References}

1. Turkmen, A. Karagoz, A. Kucuk. Sirtuins as novel players in the pathogenesis of diabetes mellitus, World J. Diabetes. 2014; 5 (6): 894-900.

2. S. Skyler, C. Oddo. Diabetes trends in the USA, Diabetes Metab. Res. Rev. 2002; Suppl 3:S21-6.

3. International Diabetes Federation (IDF) (2015) Diabetes Atlas. 7th Edition, vol 144. International Diabetes Federation, Brussels.

4. Black BL, Croom J, Eisen EJ, et al. Differential effects of fat and sucrose on body composition in $\mathrm{A} / \mathrm{J}$ and C57BL/ 6 mice. Metabolism. 1998; 47:1354-1359.

5. Roberts CK, Berger JJ, Barnard RJ. Long-term effects of diet on leptin, energy intake, and activity in a model of diet-induced obesity. J Appl Physiol. 2002; 93:887-893.

6. Bayol SA, Farrington SJ, Stickland NC. A maternal 'junk food' diet in pregnancy and lactation promotes an exacerbated taste for'junk food' and a greater propensity for obesity in rat offspring. $\mathrm{Br}$ J Nutr. 2007; 98:843-851.

7. Artunc F, Schleicher E, Weigert C, Fritsche A, Stefan N, Häring HU. The impact of insulin resistance on the kidney and vasculature. Nat Rev Nephrol. 2016;12(12):721-737.

8. Grinder-Hansen L, Ribel-Madsen R, Wojtaszewski JF, et al. A common variation of the PTEN gene is associated with peripheral insulin resistance. Diabetes Metab. 2016;42(4):280-4.

9. Song $P, W u Y, X u J$, et al. Reactive nitrogen species induced by hyperglycemia suppresses Akt signaling and triggers apoptosis by upregulating phosphatase PTEN (phosphatase and tensin homologue deleted on chromosome 10) in an LKB1-dependent manner. Circulation. 2007;116(14):1585-95.

10. Hu Z, Lee IH, Wang $X$, et al. PTEN expression contributes to the regulation of muscle protein degradation in diabetes. Diabetes. 2007;56(10):2449-56.

11. Hu $\mathrm{Z}$, Wang $\mathrm{H}$, Lee $\mathrm{IH}$, et al. PTEN inhibition improves muscle regeneration in mice fed a high-fat diet. Diabetes. 2010;59(6):1312-20.

12. Lin HT, Otsu M, Nakauchi H. Stem cell therapy: An exercise in patience and prudence. Philos Trans $R$ Soc Lond B Biol Sci. 2013; 368(1609): 20110334.

13. Bi S, Nie Q, Wang WQ, et al. Human Umbilical Cord Mesenchymal Stem Cells Therapy for Insulin Resistance: A Novel Strategy in Clinical Implication. Curr Stem Cell Res Ther. 2018;13(8):658-664.

14. WenBo W, Fei Z, YiHeng D, et al. Human Umbilical Cord Mesenchymal Stem Cells Overexpressing Nerve Growth Factor Ameliorate Diabetic Cystopathy in Rats. Neurochem Res. 2017; 42(12): 3537-47.

15. Chen $P$, Huang $Q, X u X J$, et al. The effect of liraglutide in combination with human umbilical cord mesenchymal stem cells treatment on glucose metabolism and $\otimes$ cell function in type 2 diabetes mellitus. Zhonghua Nei Ke Za Zhi. 2016; 55(5): 349-54. 
16. Wang $X$, Yin $X$, Sun $W$, et al. Intravenous infusion umbilical cord-derived mesenchymal stem cell in primary immune thrombocytopenia: A two-year follow-up.Exp Ther Med. 2017;13(5):2255-2258.

17. Braid LR, Wood CA, Wiese DM, et al. Intramuscular administration potentiates extended dwell time of mesenchymal stromal cells compared to other routes. Cytotherapy. 2018;20(2):232-244.

18. Antunes LC, Elkfury JL, Jornada MN, et al. Validation of HOMA-IR in a model of insulin-resistance induced by a high-fat diet in Wistar rats. Arch Endocrinol Metab. 2016;60(2):138-42.

19. Osborn and J. M. Olefsky. The cellular and signaling networks linking the immune system and metabolism in disease. Nature Medicine. 2012;18(3), pp. 363-374.

20. Xia JY, Morley TS, Scherer PE. The adipokine/ceramide axis: key aspects of insulin sensitization. Biochimie. 2014;96(1):130-139.

21. Wang N, Li Y, Li Z, et al. IRS-1targets TAZ to inhibit adipogenesis of rat bone marrow mesenchymal stem cells through PI3K-Akt and MEK-ERK pathways. Eur J Pharmacol. 2019;849:11-21.

22. Emamgholipour S, Ebrahimi R, Bahiraee A, et al. Acetylation and insulin resistance: a focus on metabolic and mitogenic cascades of insulin signaling. Crit Rev Clin Lab Sci. 2020; 2:1-19.

23. Weng LP, Smith WM, Brown JL, et al. PTEN inhibits insulin-stimulated MEK/MAPK activation and cell growth by blocking IRS-1 phosphorylation and IRS-1/Grb-2/Sos complex formation in a breast cancer model. Hum Mol Genet. 2001;10(6):605-16.

24. Bader AM, Klose K, Bieback K, et al. Hypoxic Preconditioning Increases Survival and Pro-Angiogenic Capacity of Human Cord Blood Mesenchymal Stromal Cells In Vitro. PLoS One. 2015; 10: e0138477.

25. Vangsness CT Jr, Sternberg H and Harris L. Umbilical Cord Tissue Offers the Greatest Number of Harvestable Mesenchymal Stem Cells for Research and Clinical Application: A Literature Review of Different Harvest Sites. Arthroscopy. 2015; 31: 1836-1843.

26. Fazzina R, Mariotti A, Procoli A, et al. A new standardized clinical-grade protocol for banking human umbilical cord tissue cells. Transfusion. 2015; 55(12):2864-73.

27. Guo G, Zhuang X, Xu Q, et al. Peripheral infusion of human umbilical cord mesenchymal stem cells rescues acute liver failure lethality in monkeys.Stem Cell Res Ther. 2019;10(1):84.

28. Xu L, Xing Q, Huang T, et al. HDAC1 Silence Promotes Neuroprotective Effects of Human Umbilical Cord-Derived Mesenchymal Stem Cells in a Mouse Model of Traumatic Brain Injury viaPI3K/AKT Pathway.Front Cell Neurosci. 2019;12:498.

29. Huang Z, Liu H, Zhang X, et al. Transcriptomic analysis of lung tissues after hUC-MSCsand FTY720 treatment of lipopolysaccharide-induced acute lung injury in mouse models. Int Immunopharmacol. 2018;63:26-34.

30. Lalu MM, McIntyre L, Pugliese C, et al. Safety of cell therapy with mesenchymal stromal cells (SafeCell): a systematic review and meta-analysis of clinical trials. PLoS ONE. 2012;7:e47559.

31. Hare JM, Traverse JH, Henry TD, et al. A randomized, double-blind, placebocontrolled, doseescalation study of intravenous adult human mesenchymal stem cells (prochymal) after acute myocardial infarction. J Am Coll Cardiol. 2009;54:2277-86. 
32. Ra JC, Shin IS, Kim SH, et al. Safety of intravenous infusion of human adipose tissue-derived mesenchymal stem cells in animals and humans. Stem Cells Dev. 2011;20:1297-308.

33. Tolar J, Le Blanc K, Keating A, et al. Concise review:hitting the right spot with mesenchymal stromal cells. Stem Cells. 2010;28:1446-55.

34. de Girolamo L, Lucarelli E, Alessandri G, et al. Mesenchymal stem/stromal cells:a new "cells as drugs" paradigm. Efficacy and critical aspects in cell therapy. Curr Pharm Des. 2013;19:2459-73.

35. Kurtz A. Mesenchymal stem cell delivery routes and fate. Int J Stem Cells. 2008;1:1-7.

36. Braid LR, Wood CA, Wiese DM, et al. Intramuscular administration potentiates extended dwell time of mesenchymal stromal cellscompared to other routes. Cytotherapy. 2018;20(2):232-244.

37. Elman JS, Murray RC, Wang F, et al. Pharmacokinetics of natural and engineered secreted factors delivered by mesenchymal stromal cells. PLoS ONE. 2014;9:e89882.

38. Lee RH, Pulin AA, Seo MJ, et al. Intravenous hMSCs improve myocardial infarction in mice because cells embolized in lung are activated to secrete the anti-inflammatory protein TSG-6. Cell Stem Cell. 2009;5:54-63.

39. Schrepfer S, Deuse T, Reichenspurner $\mathrm{H}$, et al. Stem cell transplantation: the lung barrier. Transplant Proc. 2007;39:573-6.

40. Gao J, Dennis JE, Muzic RF, et al. The dynamic in vivo distribution of bone marrow-derived mesenchymal stem cells after infusion. Cells Tissues Organs. 2001;169:12-20.

41. Eggenhofer E, Benseler V, Kroemer A, et al. Mesenchymal stem cells are short-lived and do not migrate beyond the lungs after intravenous infusion.Front Immunol. 2012;3:297.

42. Francois $S$, Bensidhoum M, Mouiseddine $M$, et al. Local irradiation not only induces homing of human mesenchymal stem cells at exposed sites but promotes their widespread engraftment to multiple organs: a study of their quantitative distribution after irradiation damage. Stem Cells. 2006;24:1020-9.

43. Kean TJ, Lin P, Caplan Al, et al. MSCs: delivery routes and engraftment, cell-targeting strategies, and immu nemodulation. Stem Cells Int. 2013;2013:732742.

44. Braid LR, Hu WG, Davies JE, et al. Engineered mesenchymal cells improve passive immune protection against lethal Venezuelan equine encephalitis virus exposure. Stem Cells Transl Med. 2016;5:1026-35.

45. Spranger J, Kroke A, Mohlig M, et al. Inflammatory cytokines and the risk to develop type 2 diabetes: results of the prospective population-based European Prospective Investigation into Cancer and Nutrition (EPIC)-Potsdam Study. Diabetes. 2003;52(3):812-7.

46. Wellen KE, Hotamisligil GS. Inflammation, stress, and diabetes. J Clin Invest. 2005;115:1111-9.

47. Lontchi-Yimagou E, Sobngwi E, Matsha TE, et Diabetes mellitusand inflammation. Curr Diab Rep. 2013;13(3):435-44.

48. Hotamisligil GS, Shargill NS, Spiegelman BM. Adipose expression of tumor necrosis factor-alpha: direct role in obesity-linked insulin resistance. Science. 1993;259:87-91. 
49. Visser M, Bouter LM, McQuillan GM, et al. Elevated C-reactive protein levels in overweight and obese adults. JAMA. 1999;282:2131-5.

50. Sun XJ, Rothenberg P, Kahn CR, et al. Structure of the insulin receptor substrate IRS-1 defines a unique signal transduction Nature. 1991;352: 73-77

51. Burgering BMT, Coffer PJ. Protein kinase B (c-Akt) in phosphatidylinositol-3-OH kinase signal Nature. 1995; 376: 599-602

52. Biddinger SB, Kahn CR. From mice to men: insights into the insulin resistance syndromes. Annu Rev Physiol.2006; 68:123-158

53. Franke TF, Yang SI, Chan TO, et al. The protein kinase encoded by the Akt proto-oncogene is a target of the PDGF-activated phosphatidylinositol 3-kinase. 1995; 81: 727-736

54. Aguirre V, Uchida T, Yenush L, et al. The c-Jun NH2-terminal kinase promotes insulin resistance during association with insulin receptor substrate-1 and phosphorylation of Ser307. J Biol Chem. 2000; 275: 9047

55. Hirosumi J, Tuncman G, Chang L, et al. A central role for JNK in obesity and insulin resistance. 2002; 420: $333-336$

56. Fujishiro $M$, Gotoh $\mathrm{Y}$, Katagiri $\mathrm{H}$, et al. Three mitogenactivated protein kinases inhibit insulin signaling by different mechanisms in 3T3-L1 adipocytes. Mol Endocrinol. 2003; 17: 487

57. Lee YH, White MF. Insulin receptor substrate proteins and diabetes. Arch Pharm Res. 2004;27:361370.

58. Abel ED, Peroni O, Kim JK, et al. Adipose-selective targeting of the GLUT4 gene impairs insulin action in muscle and liver. Nature. 2001;409:729-733.

59. Neufer PD, Carey JO, Dohm GL. Transcriptional regulation of the gene for glucose transporter GLUT4 in skeletal muscle. Effects of diabetes and fasting. J Biol Chem. 1993;268:13824-13829.

60. Cheng Z, Guo S, Copps K, et al. Foxo1 integrates insulin signaling with mitochondrial function in the liver. Nat Med. 2009;15:1307-1311.

61. Hagiwara A, CornuM, Cybulski N, et al. Hepatic mTORC2 activates glycolysis and lipogenesis through Akt, glucokinase, and SREBP1c.Cell Metabolism. 2012; 15:725-738.

62. Vasconsuelo A, Milanesi L, Boland R. 17Beta-estradiol abrogates apoptosis in murine skeletal muscle cells through estrogen receptors: role of the phosphatidylinositol 3-kinase/Akt pathway. $\mathrm{J}$ Endocrinol 2008;196:385-97.

63. Ozaki KI, Awazu M, Tamiya M, et al. Targeting the ERK signaling pathway as a potential treatment for insulin resistance and type 2 diabetes. Am J Physiol Endocrinol Metab. 2016;310:E643-e651.

64. Solinas G, Becattini B. JNK at the crossroad of obesity, insulin resistance, and cell stress response. Mol Metab. 2017;6:174-184.

65. Chen S, Cavazza E, Barlier C, et al. Beside P53 and PTEN: Identification of molecular alterations of the RAS/MAPK and PI3K/AKT signaling pathways in high-grade serous ovarian carcinomas to determine potential novel therapeutic targets. Oncol Lett. 2016;12(5):3264-3272. 
66. Higgins DF, Ewart LM, Masterson E, et al. BMP7-induced-Pteninhibits Akt and prevents renal fibrosis. Biochim Biophys Acta Mol Basis Dis. 2017;1863(12):3095-3104.

67. Zhu L, Lin X, Zhi L, et al. Mesenchymal stem cells promote human melanocytes proliferation and resistance to apoptosis through PTENpathway in vitiligo. Stem Cell Res Ther. 2020;11(1):26.

68. Schultze SM, Hemmings BA, Niessen M, et al. PI3K/AKT, MAPK and AMPK signalling: protein kinases in glucose homeostasis. Expert Rev Mol Med. 2012;14:e1.

69. Yu X, Shen N, Zhang ML, et al. Egr-1 decreases adipocyte insulin sensitivity by tilting PI3K/Akt and MAPK signal balance in mice.EMBO J. 2011;30(18):3754-65.

70. Annunziata, M., Granata, R., Ghigo, E. The IGF system, Acta Diabetol. 2011;48, 1-9.

71. Boulware SD, Tamborlane WV, Rennert NJ, et al. Comparison of the metabolic effects of recombinant human insulin-like growth factor-I and insulin. Dose-response relationships in healthy young and middle-aged adults. J Clin Investig. 1994;93:1131e9.

\section{Table}

Table I. Effects of HUC-MSC transplantation on liver and kidney function in experimental mice.

\begin{tabular}{cccccc}
\hline Group & ALT & AST & $\gamma$-G T & Cre & BUN \\
\hline $\mathrm{db} / \mathrm{m}$ & $43.3 \pm 3.9$ & $160.3 \pm 27.2$ & $16 \pm 3.3$ & $15.3 \pm 2.7$ & $6.26 \pm 0.4$ \\
$\mathrm{db} / \mathrm{m}+\mathrm{HUC}-\mathrm{MSCs}$ & $69 \pm 12.8$ & $233.7 \pm 64^{*}$ & $21.7 \pm 3.3$ & $18.8 \pm 1.3$ & $9.6 \pm 0.7$ \\
$\mathrm{db} / \mathrm{db}$ & $132.7 \pm 20.7$ & $388.7 \pm 19.2$ & $28.3 \pm 2.05$ & $41 \pm 3.7$ & $8.7 \pm 0.84$ \\
$\mathrm{db} / \mathrm{db}+\mathrm{HUC}-\mathrm{MSCs}$ & $147.3 \pm 7.4$ & $387.7 \pm 31.7$ & $28 \pm 2.9$ & $58 \pm 5.7$ & $9.5 \pm 0.44$ \\
\hline
\end{tabular}

Data are presented as the mean \pm standard deviation ${ }^{*} \mathrm{P}<0.05$ vs. db/m group. HUC-MSC, human umbilical cord-mesenchymal stem cells.

\section{Figures}



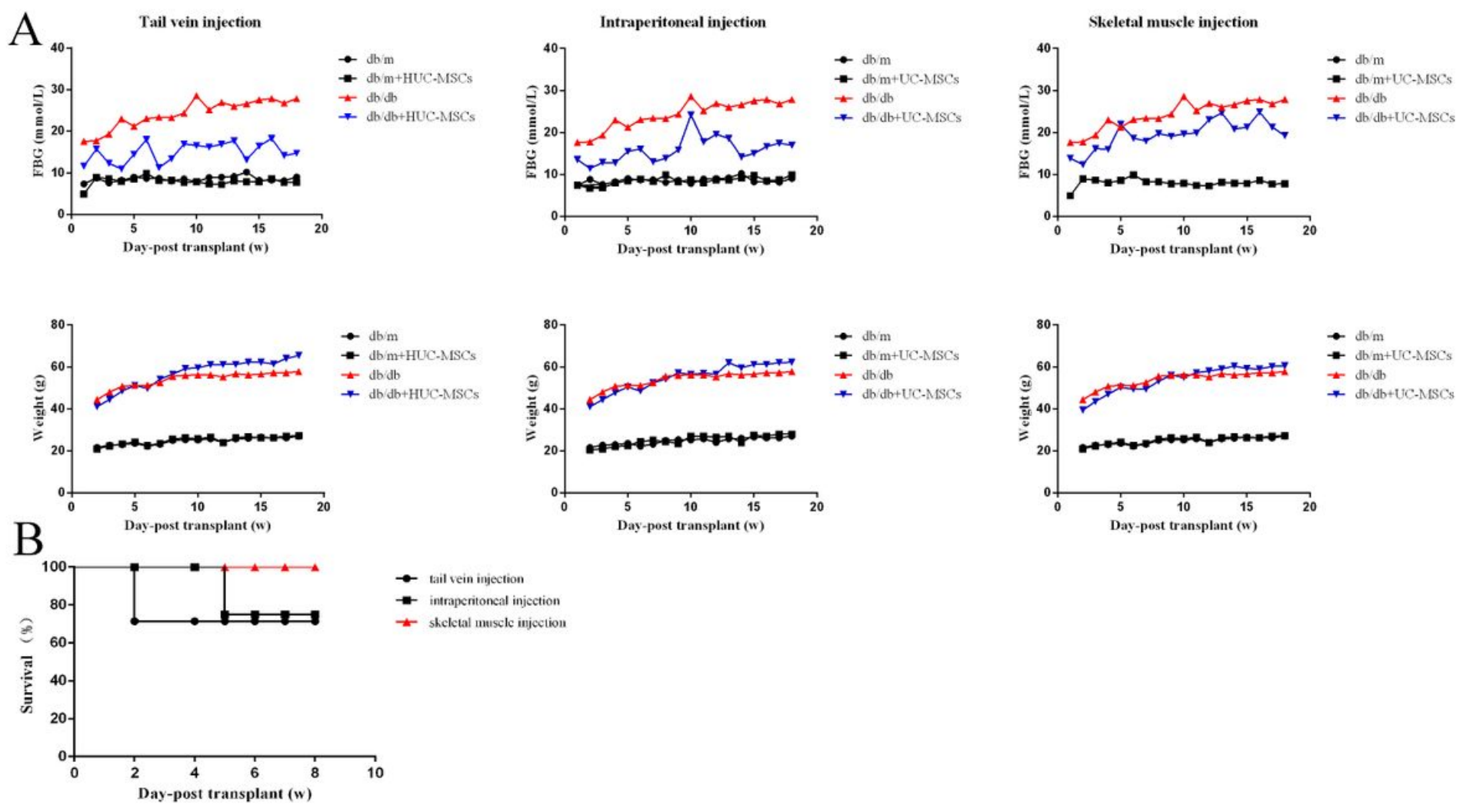

Figure 1

Therapeutic effects of HUC-MSC administration route in $\mathrm{db} / \mathrm{db}$ mice. (A) Body weight and FBG in experimental mice with HUC-MSC transplantation by IV, IP and IM. (B) Survival rates of mice administered with HUH-MSCs via the different routes. Data are representative of three repeats. IV, tail vain injection; IP, intraperitoneal injection; IM, skeletal muscle injection. HUC-MSC, human umbilical cord-mesenchymal stem cells; FBG, fasting blood glucose; IV, intravenous; IP, intra-peritoneal; IM, intramuscular. 
A

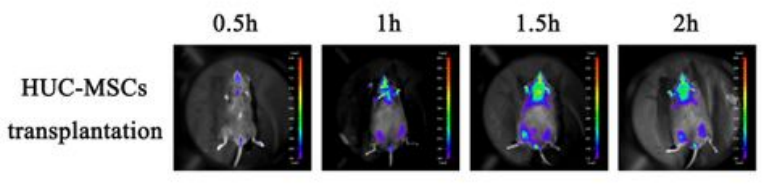

$\mathrm{C}$

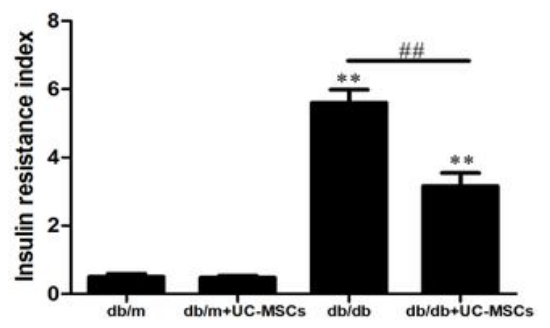

B

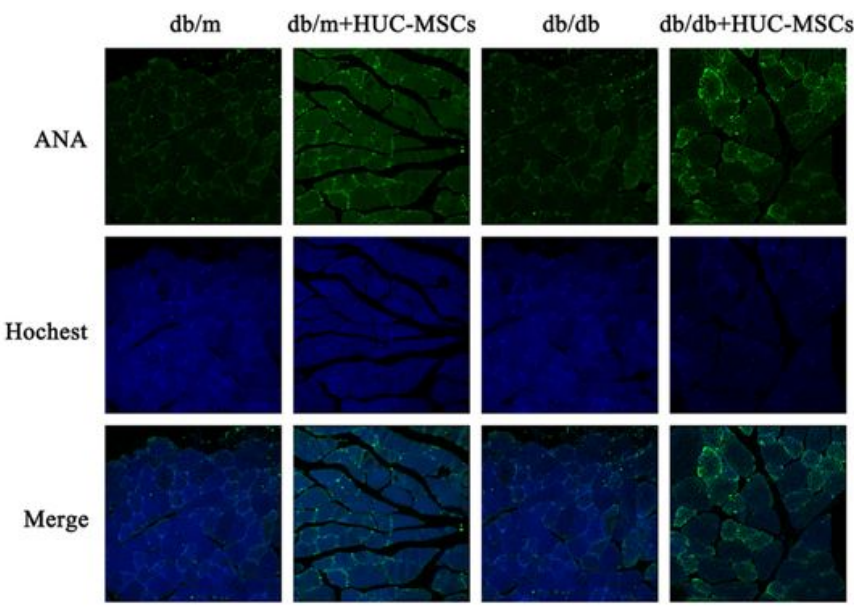

\section{Figure 2}

HUC-MSC transplantation ameliorates IR in the skeletal muscle of $\mathrm{db} / \mathrm{db}$ mice. (A) Bioluminescence imaging detected the colonization of HUC-MSCs following IM transplantation. (B) Skeletal muscle tissue sections from each mouse was stained with ANA, and assessed using immunofluorescence.

Magnification, $x 400$. (C) Insulin resistance index.. The results are representative of 3 independent repeats. Data are presented as the mean \pm standard deviation. ${ }^{*} \mathrm{P}<0.01 \mathrm{vs}$. baseline levels in $\mathrm{db} / \mathrm{m}$. $\# \# \mathrm{P}<0.01$. HUC-MSC, human umbilical cord-mesenchymal stem cells; IR, insulin resistance. 


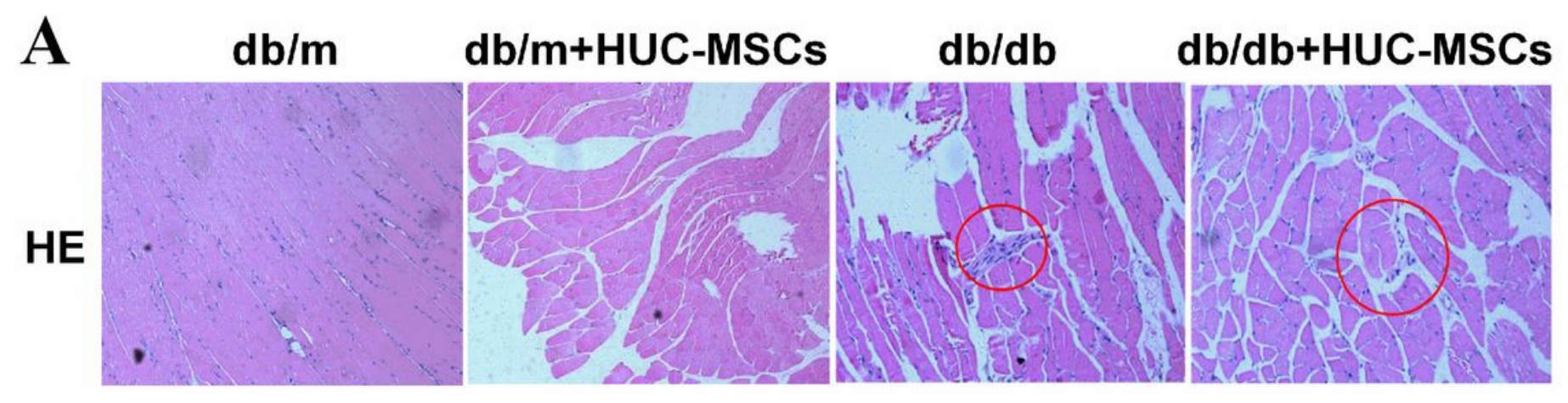

B
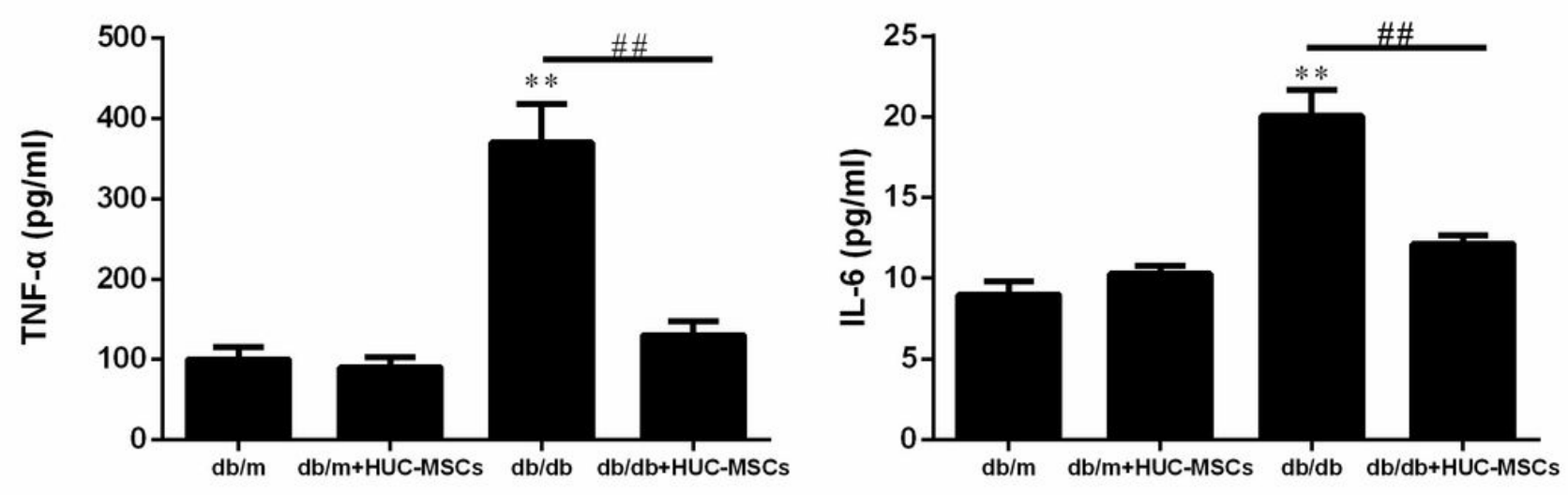

Figure 3

HUC-MSC treatment alleviates inflammation of the skeletal muscle in $\mathrm{db} / \mathrm{db}$ mice. (A) Skeletal muscle tissue sections from each rat were stained with hematoxylin and eosin. (B) TNF-a and IL-6 levels in the serum of each group. The results are representative of 3 independent experiments. Data are presented as mean \pm standard deviation. Data are presented as the mean \pm standard deviation. ${ }^{*} P<0.01$ vs. baseline levels in $\mathrm{db} / \mathrm{m}$. \#\#P<0.01. HUC-MSC, human umbilical cord-mesenchymal stem cells; IR, insulin resistance. 

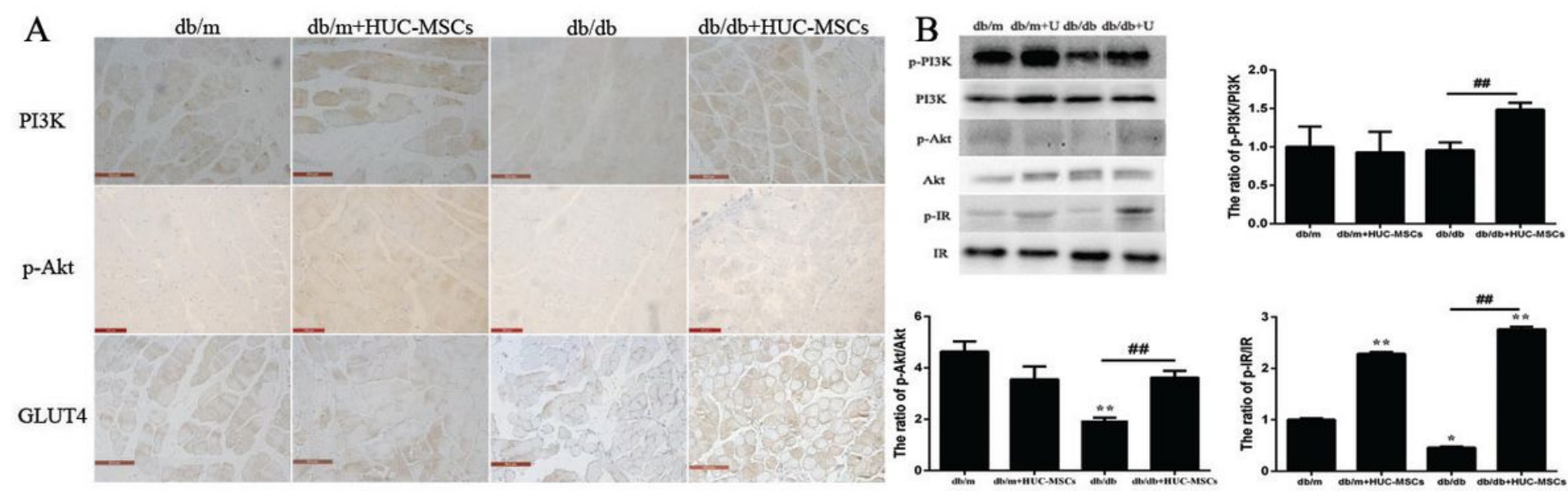

$\mathrm{C}$
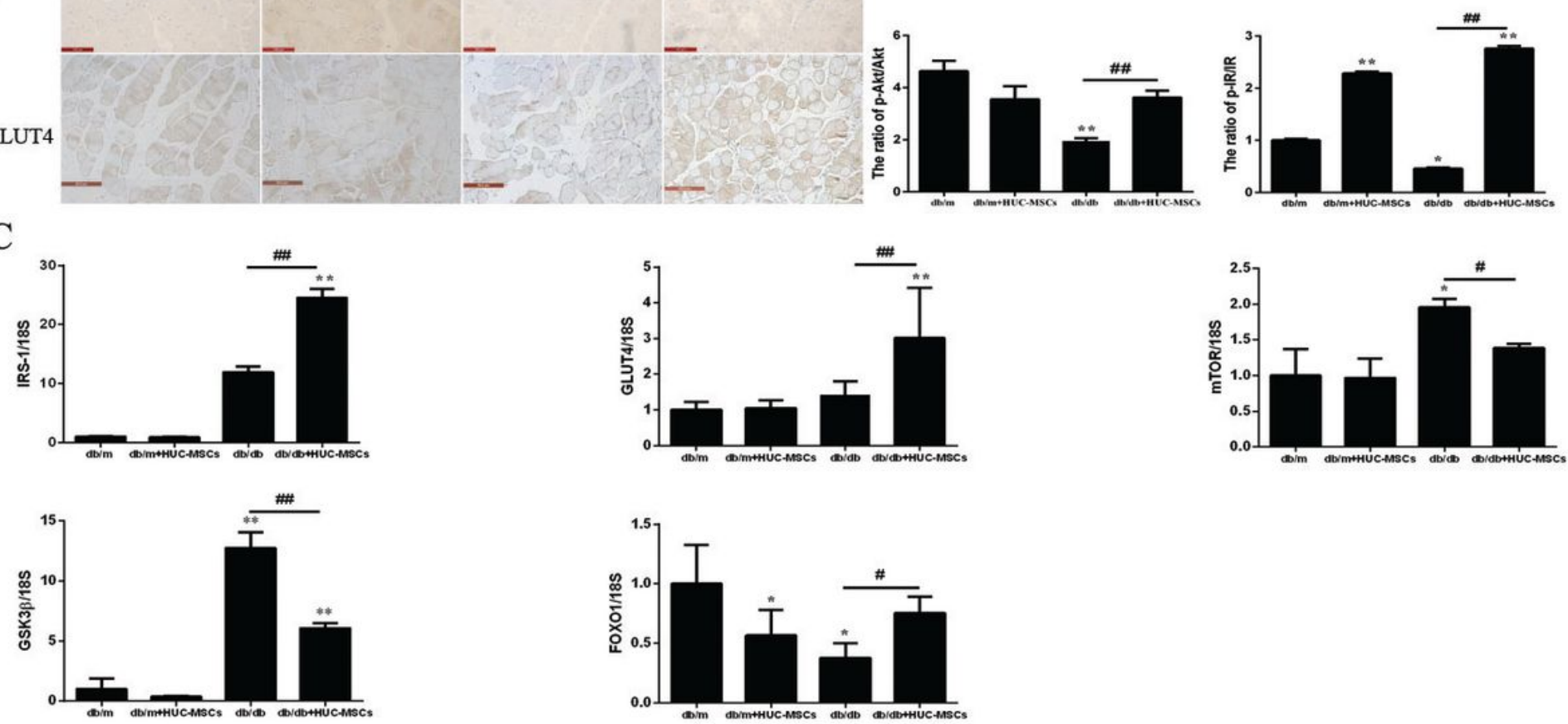

Figure 4

HUC-MSC treatment ameliorates IR through regulating the activation of PI3K/Akt signaling in the skeletal muscle of $\mathrm{db} / \mathrm{db}$ mice. (A) Fixed skeletal muscle tissues were stained with PI3K, p-Akt and GLUT4, and the intensity of immunohistochemical staining for PI3K, p-Akt and GLUT4 were evaluated based on the optical density. Representative images tissues from mice in each group are presented. Magnification, x400. (B) Protein expression levels of PI3K, p-PI3K, Akt, p-Akt, IR and p-IR in skeletal muscle tissues. (C) mRNA expression levels of IRS, GLUT4, GSK3 $\beta$, Fox01 and mTOR. ${ }^{*} P<0.05{ }^{*}{ }^{*} \mathrm{P}<0.01$ vs. the baseline levels $(\mathrm{db} / \mathrm{m})$. Data are presented as the mean \pm standard deviation. \#P<0.05, \#\#P<0.01 between $\mathrm{db} / \mathrm{db}$ and $\mathrm{db} / \mathrm{db}+\mathrm{HUC}-\mathrm{MSCs}$. The results are representative of 3 independent repeats. HUC-MSC, human umbilical cord-mesenchymal stem cells; IR, insulin receptor. 
A

$\mathrm{db} / \mathrm{m}$

$\mathrm{db} / \mathrm{m}+\mathrm{HUC} \cdot \mathrm{MSC}$ s
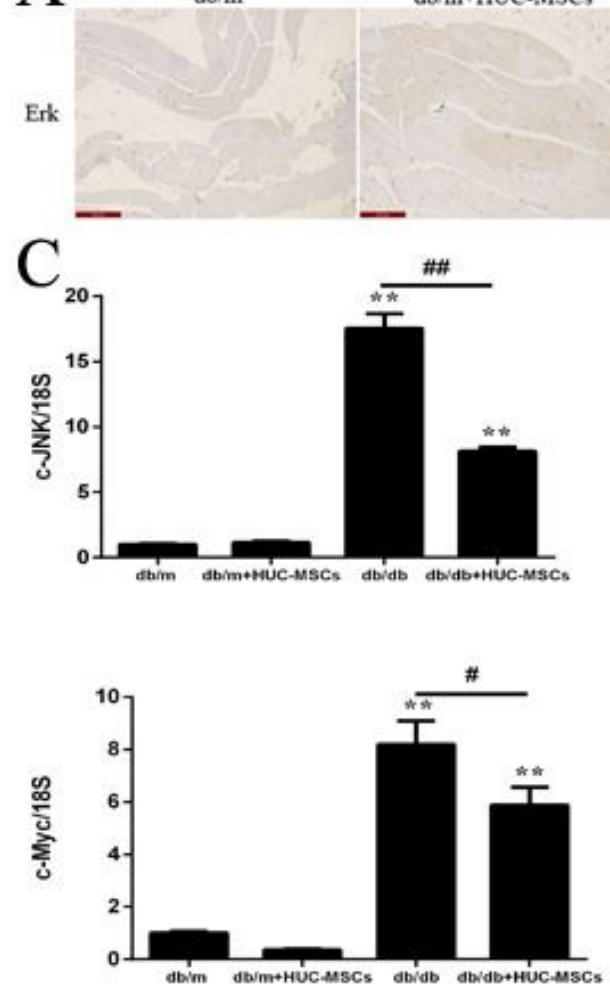

$\mathrm{db} / \mathrm{db}$

$\mathrm{db} / \mathrm{db}+$ HUC.MSCs

B $\quad d b / m \quad d b / m+U \quad d b / d b \quad d b / d b+U$

p-ERK

\section{ERK}
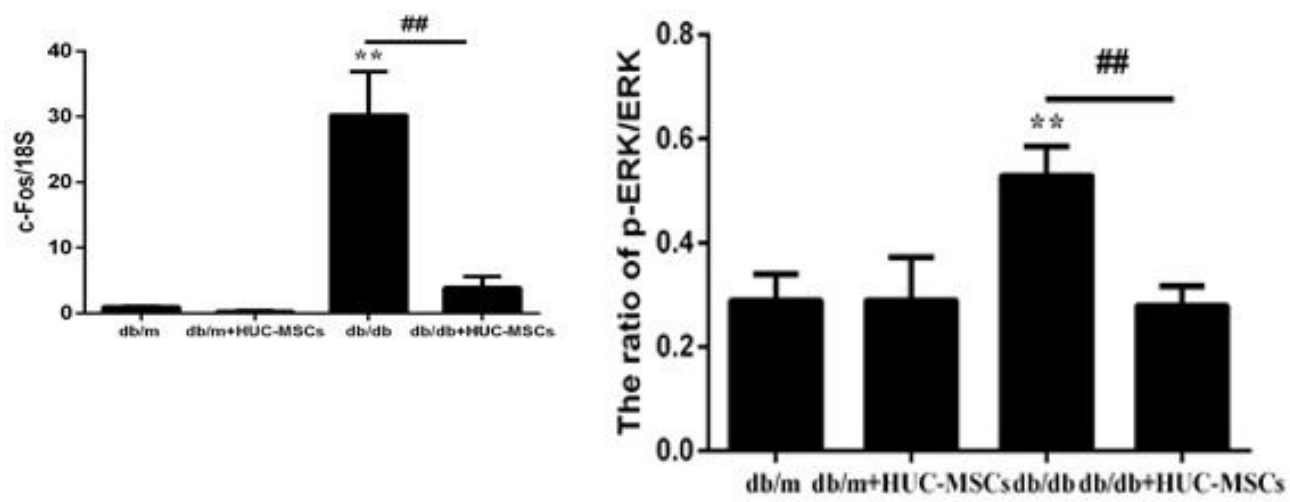

Figure 5

HUC-MSC treatment ameliorates IR through regulating the activation of ERK/MAPK signaling in the skeletal muscle of $\mathrm{db} / \mathrm{db}$ mice. (A) Fixed skeletal muscle tissues were stained with ERK, and the intensity of immunohistochemical staining for ERK was evaluated by optical density. Representative images tissues from mice in each group. Magnification, x400. (B) Skeletal muscle tissues were subjected to western blotting using specific antibodies against ERK and p-ERK. (C) mRNA expression levels of JNK, cfos and c-myc. Results are representative of 3 independent repeats. Data are presented as the mean \pm standard deviation. ${ }^{*} P<0.05 * \star P<0.01$ vs. the baseline levels $(\mathrm{db} / \mathrm{m}) ; \# P<0.05$ and $\# \# P<0.01$. 


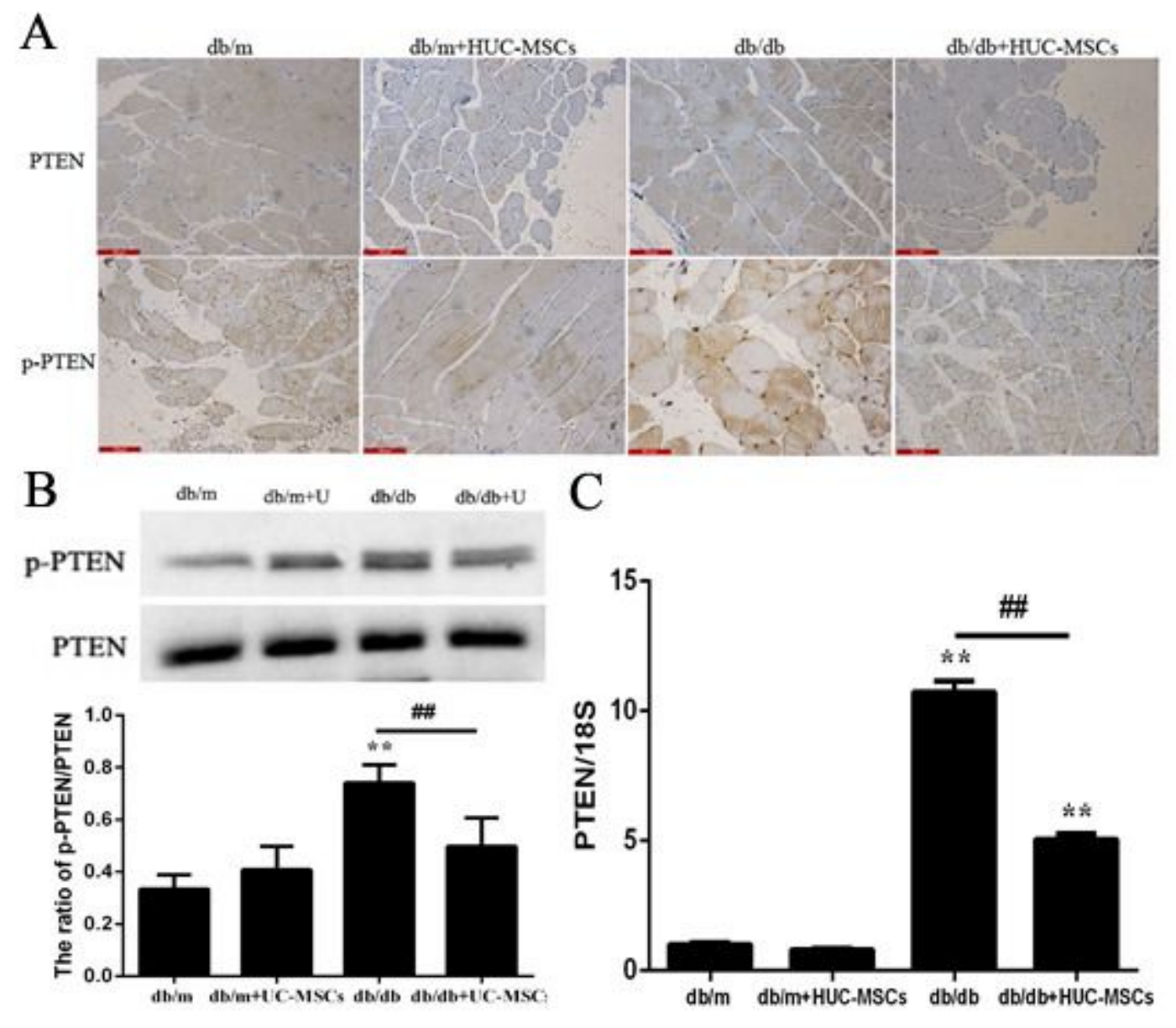

\section{Figure 6}

HUC-MSC treatment regulates the balance between PI3K/Akt and Erk/MAPK signaling by increasing PTEN expression in the skeletal muscle of $\mathrm{db} / \mathrm{db}$ mice. (A) Fixed skeletal muscle tissues were stained with PTEN and p-PTEN antibodies, and the intensity of immunohistochemical staining was evaluated. Representative images of tissues from each group. Magnification, $x 400$. (B) PTEN and $p$-PTEN protein expression levels in skeletal muscle tissues. (C) mRNA expression levels of PTEN in skeletal muscle tissues. Results are representative of 3 independent repeats. Data are presented as the mean \pm standard deviation. ${ }^{*} P<0.05 * * P<0.01$ vs. the baseline levels $(d b / m) . \# P<0.05, \# \# P<0.01$. 


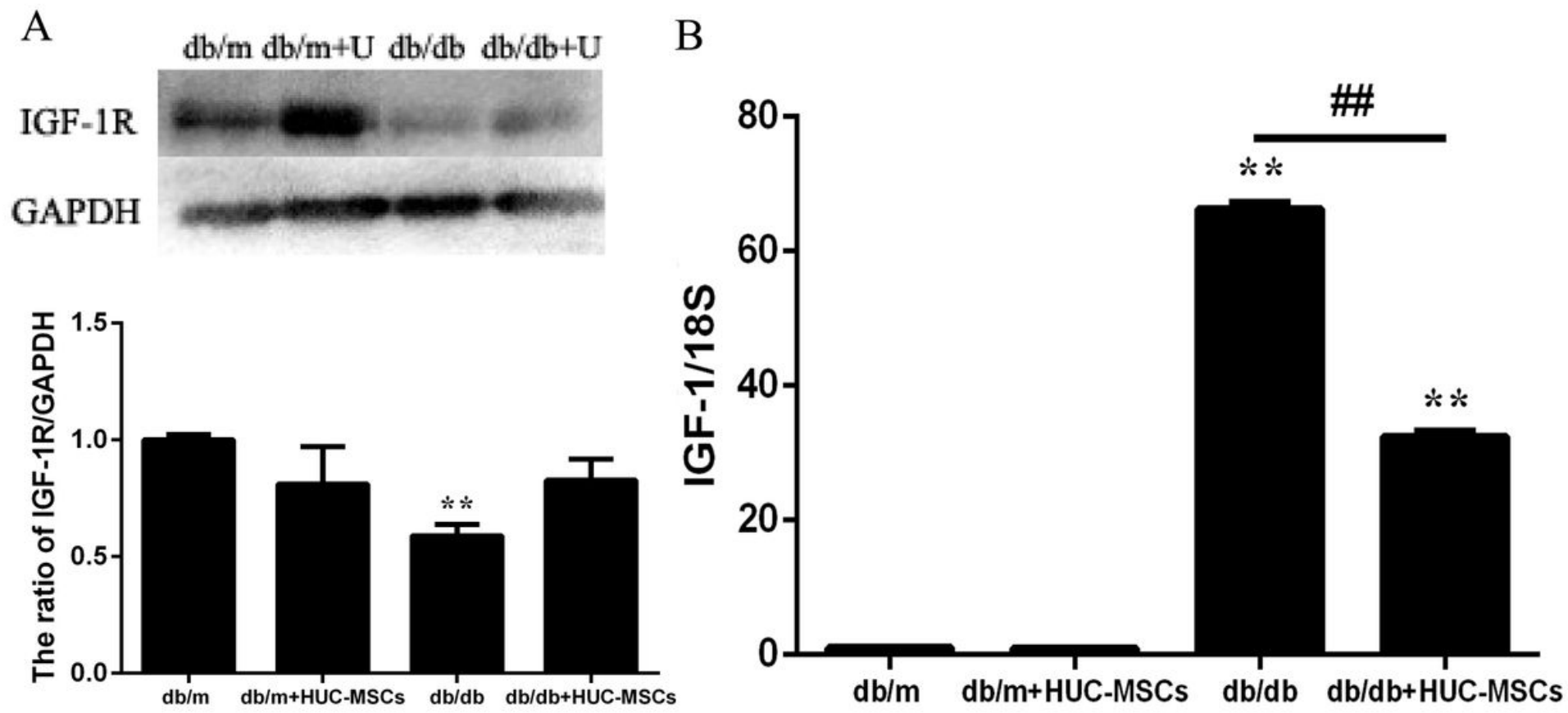

Figure 7

HUC-MSC treatment ameliorates IR, and this does not involve the IGF-1/IGF-1R pathway. (A) Protein and (B) mRNA expression levels of IGF-1R in skeletal muscle tissues. Results are representative of 3 independent repeats. Data are presented as the mean \pm standard deviation. ${ }^{*} P<0.05,{ }^{*} P<0.01$ vs. the baseline levels $(\mathrm{db} / \mathrm{m})$. \#P<0.05, \#\#P<0.01. 